\title{
Research on Structural Order Degree of Armored Vehicle PHM System Based on the Structural Entropy
}

\author{
Yuanhong Liu*, Qian Yan and Dongli Duan \\ Equipment Engineering of Institute, Armed Police Engineering University, Xi'an 710086 China
}

\begin{abstract}
The PHM (Prognostic and Health Management) system structure of armored vehicle has a very important influence on the reliability, security, mission success and life cycle cost of armored vehicle system. In view of the lack of scientific evaluation method for armored vehicde PHM system structure, a structural entropy method is proposed to evaluate PHM system structure of armored vehicle. Firstly, The PHM system structure of armored vehicles is analyzed, then the aging, quality and order degree of two typical PHM system structures are calculated by using structure entropy theory in order to obtain the order degrees, which provides theoretical basis for the structural optimization and scheme selection of PHM system structures. The results of case analysis show that the distributed PHM system of armored vehides has higher order degree than PHM system of armored vehicles.
\end{abstract}

Keywords-armored vehicle; prognostic and health management; structural entropy; order degree

\section{INTRODUCTION}

With the rapid develop ment of information technology and automation technology, the technical integration and complexity of armored vehicles are increasing, and the problems of online maintenance support are increasingly prominent. For example, the collection of state information is difficult and incomplete, the use of equipment is difficult to supervise, the troubleshooting of failures is inefficient and the cost of maintenance support has increased dramatically. Therefore, how to ensure the normal and sustained play of overall equipment effectiveness has become a hot spot researched by experts in related fields. The technology of prognostic and health management (PHM) comes into being, and continuous to grow and develop. PHM system based on the PHM technology has been gradually applied in fields of national defense and industry, and has initially shown its great development potential and application prospect ${ }^{[1]}$. The problem to be solved to develop PHM technology and system is how to evaluate PHM systemscientifically and rationally.

According to the different application objects of PHM, the commonly used PHM architectures include architectures based on logical laying, model reasoning and open architecture based on OSA-CBM ${ }^{[2-5]}$. From the point of view of system division, armored vehicles generally consist of power device, transmission device, mobile device, operating device, electrical system, fire control system, weapon system, communication and alerting system, optical systems, car body, turret, three prevention device and special devices. Armored vehicles have various functions and complex structure. PHM system structure is different when used in different composition of armo red vehicles, resulting in the full life-span cycle cost of PHM system are different. The organizational structure of PHM system has a very important impact on the reliability, security, mission success, full life-span cycle cost and other characteristics of the system.

The concept of entropy was originally used as a state parameter to describe and judge thermodynamics, and then it was rooted in statistical physics and information theory until it was used to describe the complexity of the state of matter system. As the best measure of uncertainty and information, the form of entropy is varied [7-9]. Entropy is also an effective index for measuring system organization. The system structure hierarchy and span are different, and the amount of information on each layer is also different, resulting in the timeliness and accuracy of information circulation obvious difference. The timeliness is used to indicate effectiveness of system information in terms of circulation aging, and the quality is used to indicate the order of system in formation in terms of circulation accuracy. The combination of both of them is the order degree of the system structure, so the order degree of system organization structure is different ${ }^{[10-12]}$. This paper presents an evaluation method of structural order degree of armored vehicle PHM system based on structural entropy. Based on the application scope and structure characteristics of the PHM system of armored vehic les, the structural entropy of different PHM architectures is analyzed and compared, and the main factors influencing the complexity and timeliness of PHM system are determined, which provide the basis for the design and evaluation of PHM system.

\section{ARMORED VEHICLE PHM SYSTEM STRUCTURE}

Armored vehicle with diverse functions and complex structure, is composed of tens of thousands of components. If all the components are incorporated into the PHM system, the reliability of the armored vehicle will be reduced. Therefore, at the beginning of the design of armored vehicle PHM system, appropriate "application object" for PHM technology should be designated, that is, focusing on which systems or components to preferentially apply PHM technology. From the point of view of "fault frequency", armored vehicle PHM system should focus on the application of the object for the power plant, electrical systems, mobile devices, transmission, fire control system ${ }^{[13]}$. 
Similar to the PHM system structure of the US Army's improvement plan and the US F-35 fighter, armored vehicle PHM system is mainly composed of the vehicle (airborne) PHM and ground PHM ${ }^{[13]}$. The vehicle section completes the acquisition and processing of the raw data, obtains the health information of the subsystem, displays it to the occupant in real time, and transmits it to the ground part of the PHM system when necessary. The ground PHM part receives the data of the vehicle part through the wired and wire less links, and carries on the thorough comprehensive analysis to obtain the comprehensive information of fault diagnosis, the health assessment and the life forecast. At the same time, the ground PHM system obtains the maintenance decision information through the maintaining and supporting decision-making system, coordinates maintenance departments and equipment security departments to make prompt and timely maintenance. The ground PHM part is mainly composed of ground PHM platform, off-line diagnosis module, off-line prediction module, off-line health assessment module, maintenance decision module and data storage module. According to the armored vehicle structure, the vehicle PHM part is divided into two kinds of centralized and distributed. Centralized PHM system, as shown in Figure 1, uses a computer to complete the task of data acquisition, fault diagnosis, fault prediction, health assessment, data storage and transmission of different components of the vehicle.

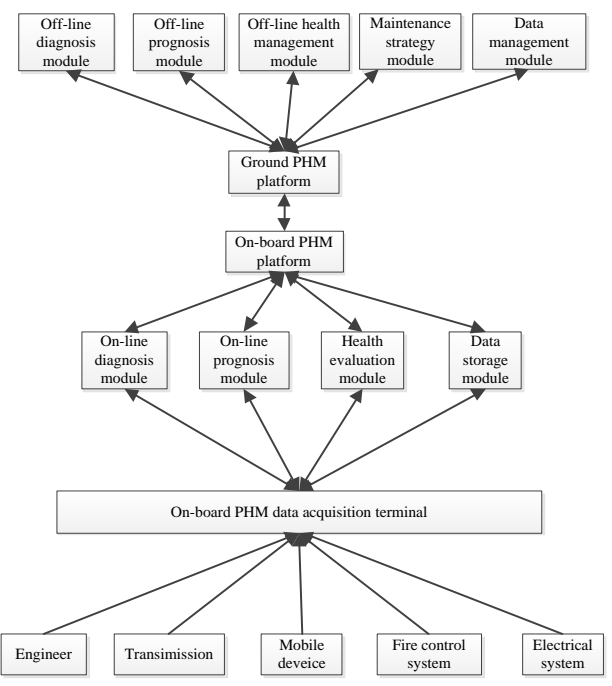

FIGURE I. CENT RALIZED PHM SYSTEM OF ARMORED VEHICLE

Distributed vehicle PHM, as shown in Figure 2, according to the composition of the armored vehicle system, uses multiple computers to complete the the task of the data acquisition, fault diagnosis, fault prediction, health assessment and data storage of composition of the armored vehicle, and transmits the results to the ground PHM.

The more the structural level of the PHM system in the armored vehicle, the more the number of times the information is transferred between the upper and lower levels, and the timeliness of the information flow will decrease. On the contrary, if the system structure level is reduced, the timeliness of information flow will be enhanced. However, because the reduction of the system structure level will increase the span of each structure, the intersection of information will increase, and the accuracy of the flow of information will be affected. That is to say, the span of each layer in the system and the number of system structure layers are important factors that affect the flow of information. Therefore, the order of the structure of armored vehicle PHM systemshould be analyzed from these two aspects.

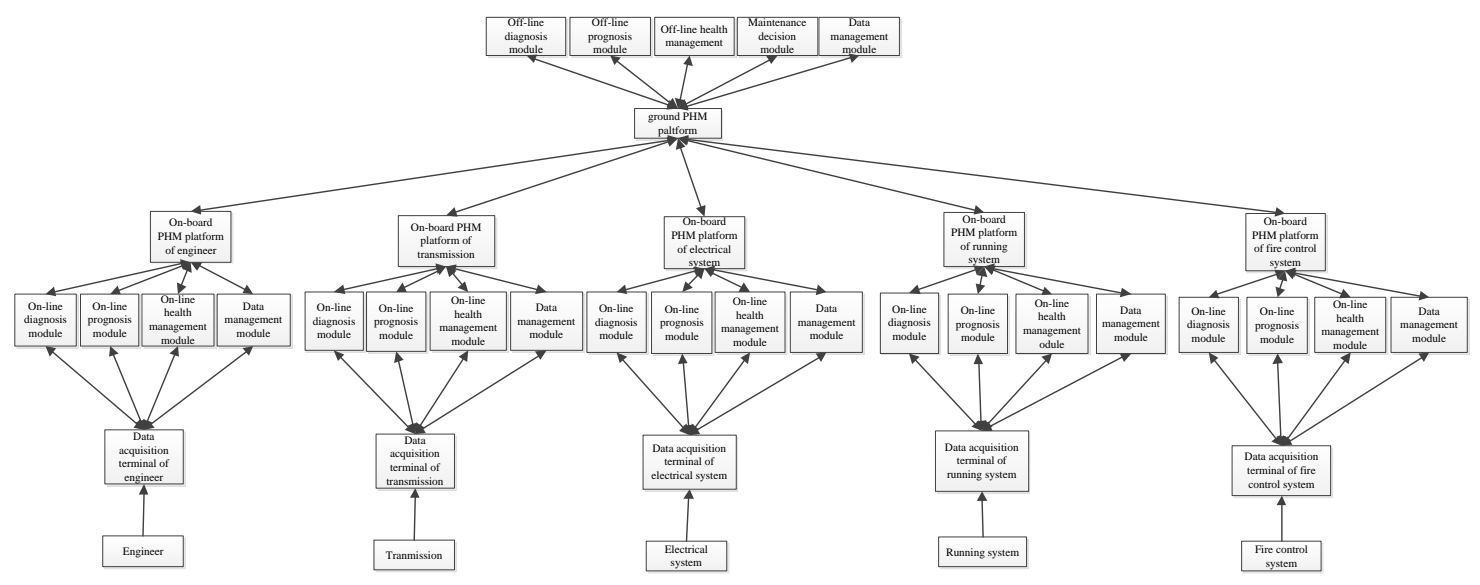

FIGURE II. DIST RIBUTED PHM SYST EM OF ARMORED VEHICLE 


\section{THE BASIC THEORY OF STRUCTURAL ENTROPY}

In the theory of structural entropy, the direct information flow between any two elements of the system is defined as the contact, and the connection number of any two elements is the contact length. If the two elements in the system are directly linked, the length of the connection is 1 , and the length of each transfer is increased by one. The connection span of an element in the system is the number of elements with the length of 1 in the system. The aging of the system structure is the velocity of circulation of the information in each element of the system, and the aging entropy of the system is the uncertainty measure of the time when the information flows in the system. The aging entropy of elements $i$ and $j$ in the systemis as follows ${ }^{[11]}$ :

$$
H_{t}(i j)=-P_{t}(i j) 1 b P_{t}(i j)
$$

In the formula, $P_{t}(i j)$ is the realization probability of the aging microscopic state between the system element $i$ and $j$.The expression is as follows:

$$
P_{t}(i j)=L_{i j} / A_{t}
$$

In the formula, $L_{i j}$ is the contact length of the element $i$ and $j, A_{t}$ is the number of aging state in the system. Its expression is as follows:

$$
A_{t}=\sum_{\substack{j=1 \\ j \neq i}}^{n} \sum_{i=1}^{n} L_{i j}
$$

$n$ in the formula is the number of elements in the structure of the system. The system aging $R_{t}$ is expressed as follows:

$$
R_{t}=1-H_{t s u m} / H_{t \max }
$$

In the formula, $H_{t s u m}$ is the total aging entropy of the system, and its expression is as follows:

$$
H_{\text {tsum }}=\sum_{\substack{j=1 \\ j \neq i}}^{n} \sum_{i=1}^{n} H_{t}(i j)
$$

$H_{t \max }$ is the maximum aging entropy of the system, and its expression is as follows:

$$
H_{t \max }=1 b\left(A_{t}\right)
$$

The quality of the system structure is the accuracy of the information circulation in the system, and the quality entropy is the uncertainty measure of accuracy. In the system, $H_{m}(i)$ is the quality entropy of the element $i$,its expression is as follows.

$$
H_{m}(i)=-P_{m}(i) l b P_{m}(i)
$$

In the formula, $P_{m}(i)$ is the implementation probability of the quality microscopic state of the $i$ thelement, and its expression is as follows:

$$
P_{m}(i)=K(i) / A_{m}
$$

In the formula, $K(i)$ is the connection span of the element $i$ in the system structure. $A_{m}$ is the the sum of the links of the elements in the system, and its expression is as follows:

$$
A_{m}=\sum_{i=1}^{n} K(i)
$$

System quality $R_{m}$ is expressed as follows:

$$
R_{m}=1-H_{m s u m} / H_{m \max }
$$

In the formula, $H_{\text {msum }}$ is the total quality entropy of the system, and its expression is as follows.

$$
H_{m s u m}=\sum_{i=1}^{n} H_{m}(i)
$$

$H_{m \max }$ is the maximum quality entropy of the system, and its expression is as follows:

$$
H_{m \max }=1 b\left(A_{m}\right)
$$

The degree of order of the system structure expressed by $R$ is a comprehensive measure of the uncertainty of system aging and systemquality, and its expression is as follows:

$$
R=\alpha R_{t}+\beta R_{m}
$$

In the formula, $\alpha, \beta$ are weighting coefficients of system aging and quality.

\section{CASE ANALYSIS}

In the structure model of armored vehic le PHM system, the information more flow between the upper and lower layers, 
and the horizontal link between the layers and jump-layer circulation are less. Therefore, in order to build the structure model of armored vehicle PHM system, it is assumed that the information in the model only circulate layer by layer between the upper and lower layers, and the structural entropy theory is used to analyze the timeliness and accuracy of the information flow of the armored vehicle PHM system. In the structure, if the two elements (the nodes in the figure) are directly connected, the length of the link is 1 , increasing length by 1 each time transferring. The node's contact span is the number of elements in the structure of which contact length is 1 with this node. Thus, the maximum aging entropy, aging entropy, maximum quality entropy, quality entropy, aging, quality and order degree of armored vehicle distributed PHM system and centralized PHM system are shown in Table 1, in which the weight coefficient of aging and quality in process of the information flowing is 0.5 .

\section{T ABLE I ST RUCTURAL ENT ROPY OF DIST RIBUTED PHM SYSTEM AND CENT RALIZED PHM SYSTEM}

\begin{tabular}{|c|c|c|}
\hline Structural entropy & $\begin{array}{c}\text { Armored vehicle } \\
\text { distributed PHM } \\
\text { system }\end{array}$ & $\begin{array}{c}\text { Armored vehicle } \\
\text { centralized PHM } \\
\text { system }\end{array}$ \\
\hline $\begin{array}{c}\text { Maximum aging entropy of the } \\
\text { system } H_{t \max }\end{array}$ & 2.6990 & 2.4150 \\
\hline Aging entropy of the system $H_{\text {sum }}$ & 6.9916 & 4.130 \\
\hline $\begin{array}{l}\text { Maximum quality entropy of the } \\
\text { system } H_{m \max }\end{array}$ & 2.0212 & 1.5798 \\
\hline $\begin{array}{c}\text { Quality entropy of the system } \\
H_{m s u m}\end{array}$ & 1.5747 & 1.0756 \\
\hline System aging $R_{t}$ & 0.6140 & 0.4153 \\
\hline System quality $R_{m}$ & 0.2209 & 0.3192 \\
\hline Order degree of the system $R$ & 0.4174 & 0.3672 \\
\hline
\end{tabular}

As can be seen from Table 1, the armored vehicle distributed PHM system and centralized PHM system have the same hierarchy which is a 6-layer structure. But in the distributed PHM system, it has more structure bifurcation of the vehicle PHM platform, and system information distribution channels are more. Timeliness of information circulation is higher than that of the centralized distribution system, but the quality of information circulation is reduced. Therefore, the timeliness of the distributed PHM system structure is higher than the centralized PHM system, but the quality is lower than the centralized PHM system. In general, the distributed PHM system is more ordered than the centralized PHM system.

In the distributed PHM system, the contact span of the key factors in the quality order is up to 10 , and the corresponding system element is the PHM platform, which reflects the importance of the ground PHM platform in the distributed PHM system. In order to improve the quality and order of distributed PHM systems, the ground PHM platform in distributed PHM system should be optimized. For example, the centralized ground PHM platform can be designed to be a distributed terrestrial PHM platform. In the centralized PHM system, the contact span is up to 9, and the corresponding system ele ment is the vehicle PHM acquisition terminal. That is to say, in order to improve the overall quality of the PHM system order, it is necessary to optimize the vehic le PHM data acquisition terminal.

\section{CONCLUSION}

(1) This paper proposes an order analysis method of armored vehicle PHM system based on structural entropy, and obtains that the distributed PHM system of armored vehicles has higher order degree than centralized PHM system of armored vehicles.

(2) In the practical application, according to the nu mber of armored vehicles and PHM range of applications, armored regiment can use distributed-centralized structure in armored vehicle PHM system. The structural entropy model is used to analyze the structure of armored vehicle PHM system, which can quantitatively express the order degree of PHM system structure, and provide the theoretical basis for the structural optimization of armored vehicle PHM systemstructure.

\section{REFERENCES}

[1] F. Z. Feng, "research on PHM system index composition and Evaluation," General Equipment Department, 2015

[2] A. Hess, "The Joint Strike Fighter(JSF)PHM Concept: Potential Impact on Aging Aircraft Problems," IEEE Aerospace Conference Proceedings, vol. 6: pp. 3021-3026, 2002

[3] B.Z. Zhang, "Development and applications of integrated diagnostics, prognostics and health management technologies of abroad," Computer Measurement \& Control, vol. 16, pp. 591-594, 2008

[4] L. Zhang, F.M. Zhang, J. T Li, et.al, "Research on on-board prognostics and health management system architecture for operational aircraft," JOURVAL OF AIR FORCE ENGINEERING UNIVERSIT Y(NATURAL SCIEVCE EDITION), vol. 9, pp. 7-1 1, 2008

[5] X. W. He, Z. J. Zeng, H. Jia, et al, "Research application anti-ship on PHM in sensor technology networks of missile's maintenance support," Instrument and Meter Coust omer, vol. 14, pp. 11-13, 2007

[6] H.Z. Wang, Yang Jiangping, Wang Shihua, "Research on the maintenance support system for radar equipment based on the PHM," Journal of the Academy of Equipment Command \& Technology, vol. 19, pp. 83-86, 2008

[7] F. F. Feng, G. Q. Rao, A. W. Si, et al, "Research a testing application of the arithmetic of PF in sudden change of vibration signal," JGURNAL GF VIBRATIGN ENGINEERING, vol. 25, pp. 221-224, 2012

[8] B. R. Xu, R. L. Li, H. M. Wei, et al, "Entropy weight fuzzy comprehensive evaluation on failure mode criticality of integrated transmission system”, vol. 34, pp. 1381-1386, 2013

[9] C. Zhang, J. J. Chen, X. Guo, "A gear fault diagnosis method based on EMD energy entropy and SVM," JOURNAL OF V IBRATION AND SHOCK, vol. 29, pp. 216-221, 2010

[10] E. O. Wiley, D. Layzer, "Information in cosmology, physics and biology," Quantum Chem., vol. 12, pp. 185-195, 1988

[11] Z. F. Zhang, R. B. Xiao, "Empirical study on orderliness evaluation of production system based on structure entropy," CHINESE JOURNAL OF MECHANICAL ENGINEERING, vol. 43, pp. 62-67, 2007

[12] Y.H Qiu, Management decision-making and application Entropy theory, BeiJing: China Mechanical Press, 2002.

[13] A. W. Si, "Research on abnormal detection and fault prognostic technique in a PHM System for armored vehicle," BeiJing: Academy of Armored Forces Engineering, 2012 